\title{
The perceptions of cognitively impaired patients and their caregivers of a home telecare system
}

This article was published in the following Dove Press journal:

Medical Devices: Evidence and Research

19 December 2014

Number of times this article has been viewed

\author{
Shima Mehrabian' \\ Jocelyne Extra ${ }^{2}$ \\ Ya-Huei Wu ${ }^{2}$ \\ Maribel Pino ${ }^{2}$ \\ Latchezar Traykov' \\ Anne-Sophie Rigaud ${ }^{2}$ \\ 'Department of Neurology, University \\ Hospital (UH) "Alexandrovska", \\ Sofia, Bulgaria; 'Department of \\ Gerontology, Hôpital Broca, Assitance \\ Publique-Hôpitaux de Paris, EA 4468, \\ Faculte de Médecine, Université Paris \\ Descartes, Paris, France
}

Correspondence:Anne-Sophie Rigaud Department of Gerontology, Hôpital Broca,Assistance Publique-Hôpitaux de Paris, EA4468, Faculte de Médecine, Université Paris Descartes, 54/56 rue Pascal, 75013 Paris, France

Tel +33 | 44083503

Fax +33 I 440835 I0

Email anne-sophie.rigaud@brc.aphp.fr

\begin{abstract}
Assistive and telecare technologies have been developed to support older adults with cognitive impairments, as well as their caregivers, from their homes. The way potential users perceive telecare and smart home systems plays a key role in their acceptance of this new technology. We evaluate the acceptance of home telecare technologies among patients suffering from cognitive impairment and their caregivers. Prototypes of telecare devices were developed to demonstrate their features and capabilities and to train patients, families, and health care professionals in their use. We conducted semistructured interviews to elicit the perceptions of 30 patients with mild cognitive impairment, 32 patients with Alzheimer's disease, and 30 caregivers, regarding the risks and advantages of home telecare and smart houses. Survey results reflected participants' largely positive reactions to these technologies. Regarding home telecare, the cognitive stimulation program earned the highest proportion of positive responses, followed by the devices' care of emergencies. The participants generally agreed that home telecare and smart houses could significantly improve their quality of life. However, some technical and ethical concerns, such as the way of provision, installation, and monitoring of the systems, were reported to be in need of addressing before implementation of this system.
\end{abstract}

Keywords: home telecare, Alzheimer's disease, mild cognitive impairment, caregiver, cognitive stimulation

\section{Introduction}

As the number of patients suffering from Alzheimer's disease (AD) increases, there is a growing need for technology that will allow them to live independently in their own homes for as long as possible. With survival rates varying from 1 to 16 years after diagnosis and with increasingly incapacitating deficits, many patients require long-term care. ${ }^{1}$ The majority of persons with $\mathrm{AD}$ are cared for at home by a family member, usually a spouse or daughter. ${ }^{2}$ The demanding task of caring for the elderly, especially those suffering from cognitive impairments, cannot be solved solely by conventional methods; more cost-effective technical solutions must be considered. ${ }^{3,4}$ Home telecare is a rapidly expanding field that involves the application of telecommunications and computer technologies to the provision of effective at-home health care. ${ }^{5}$

To provide new knowledge of how home telecare technology can be designed and customized to meet the needs of users with mild cognitive impairment (MCI) or AD, as well as their caregivers, we propose a user-friendly approach that integrates human, medical, psychological, ethical, and social issues. This multidisciplinary approach will help enhance the quality of life for both caregivers and patients, as well as relieve some of the escalating burden on the social and health services. The telemonitoring 
system we have developed makes use of Internet technology, broadband communication, smart house technology, and a free in-home software module. The services provided by the telecare system are devoted to lifestyle monitoring and aim to improve patient well-being through enhancing the patient's safety and security; providing a cognitive prosthesis to the patient through medications, tasks, and appointments; training cognitive functions; monitoring health with teleconsultation between patients and health care professionals; and enhancing valuable social links. The home telecare system is easy to use and displays interfaces tailored to the needs and preferences of cognitively impaired persons. The system is composed of multiple access points connected via Internet to a server that provides services and stores related data (access point characteristics, medical files, and so on). The design of access points and servers reflects a high regard for security and confidentiality.

Home telecare is a relatively new field, and it takes time for technological innovations to be widely adopted in health care. The successful introduction of health technology requires an in-depth understanding of how the proposed innovation is perceived by the users. This is a promising method of improving quality of life, but for it to have an effect, patients and caregivers must accept it and be willing to use the equipment in their own home. It is important to examine the readiness of a cognitively impaired population to use various technologies for telecare.

Little has been published about perceived needs in this area. ${ }^{6}$ To help provide more data in this important area, we conducted semistructured interviews to elicit patients' and caregivers' opinions on the telecare system at home. This article presents results from these interviews regarding the acceptance of home telecare technologies among both patients suffering from cognitive impairment and their caregivers, as well as their willingness to adopt to such a telecare system in their homes.

\section{Population}

Potential respondents were recruited from a geriatric outpatient research unit at the Hôpital Broca in Paris, France, and included three groups: patients with $\mathrm{AD}$, patients with $\mathrm{MCI}$, and family caregivers.

Patients' cognitive status was evaluated by the Folstein Mini-Mental State Examination (MMSE) and a battery of neuropsychological screening tests designed to assess immediate and delayed memory, language, and visuoperceptual and visuospatial capacities, as well as problem-solving skills. ${ }^{7}$ The tests used were subtests and modified short forms of widely used neuropsychological measures. The neurocognitive battery was conducted by a qualified neuropsychologist. The patients also underwent a complete physical and neurological examination, including laboratory tests as well as computed tomography of the brain or magnetic resonance imaging. Patients older than 50 years were included in the study only after consensus had been reached as to their classification into one of the following diagnostic categories: the AD group (32 patients who met Diagnostic and Statistical Manual of Mental Disorders, 4 th Edition, ${ }^{8}$ criteria for Dementia of the Alzheimer's Type and National Institute of Neurological and Communicative Disorders and Stroke and Alzheimer's disease and Related Disorders Association ${ }^{9}$ criteria for probable AD; those patients with severe cognitive impairment, for instance, language deficit, were not included in the study ${ }^{8,9}$ ) and the MCI group (criteria used for the selection of the MCI patients were those proposed by the European Consortium on Alzheimer's disease $\left.{ }^{10}\right)$.

Exclusion criteria for patient's group were serious intercurrent illness, psychiatric disorders, or presence of neuropsychiatric symptoms.

In addition, 30 patients' family caregivers who were older than 50 years were recruited (spouses, adult children, other relatives). Exclusion criteria for caregivers were serious intercurrent illness or psychiatric disorders. Table 1 shows the profile of the participants.

\section{Methods}

We conducted a series of semistructured interviews to assess participants' perceptions of the usefulness of different functionalities of the telecare system. Items evaluated included perceived advantages and disadvantages of the telecare system and the degree of willingness to adopt such technology in their homes. We opted to perform interviews rather than focus groups because $\mathrm{AD}$ patients tend to be more at ease and

Table I Demographic characteristics of respondents

\begin{tabular}{|c|c|c|c|}
\hline $\begin{array}{l}\text { Respondents' } \\
\text { characteristics }\end{array}$ & $\begin{array}{l}\text { Caregivers } \\
(n=30)\end{array}$ & $\begin{array}{l}\text { Patients with } \\
\mathrm{MCl}(n=30)\end{array}$ & $\begin{array}{l}\text { Patients with } \\
\text { AD }(n=32)\end{array}$ \\
\hline \multicolumn{4}{|l|}{$\overline{\text { Sex }}$} \\
\hline Female & $20(66.6 \%)$ & $19(63.3 \%)$ & $26(81.2 \%)$ \\
\hline Male & $10(33.4 \%)$ & II (36.7\%) & $6(18.8 \%)$ \\
\hline Age & $64.1 \pm 10.21$ & $74.8 \pm 5.9$ & $77.1 \pm 7.2$ \\
\hline MMSE & & $26.4 \pm 1.7$ & $23.0 \pm 2.0$ \\
\hline \multicolumn{4}{|c|}{ Relationship to patient } \\
\hline Spouse & $21(70 \%)$ & & \\
\hline Offspring & $9(30 \%)$ & & \\
\hline
\end{tabular}

Note: Data are reported as mean \pm SD.

Abbreviations: $\mathrm{MCl}$, mild cognitive impairment; $\mathrm{AD}$, Alzheimer's disease; MMSE, Mini-Mental State Examination. 
express themselves more freely when they are alone, rather than among other patients.

The interviews conducted consisted of two parts. First, we described the objectives and characteristics of the telecare system functionalities to the participants, using easily understandable concepts to take into account their cognitive deficits. Because people with cognitive impairments are prone to misunderstandings, they were encouraged to ask questions about the system and to rephrase the explanations using their own words to ensure they had understood them.

We explained that the end-user would have access to the telecare system services (detecting some emergencies, providing cognitive stimulation exercises, enabling teleconsultation with professionals and videoconferencing with family and friends, and providing medicines and tasks reminders) through an easy-to-use computer that encompasses a touch screen as well as some sensors (front door, fire and water, fall sensors) at home. For each service, an interface was displayed on the computer (Figures 1-4) to help participants understand the purpose and the functionality of the system.

Once the system characteristics had been explained to the participants, they were asked to answer a questionnaire and were encouraged to supply comments regarding each question. We developed a 14-item survey instrument in which most of the questions required a "yes" or "no" answer (Table 2). A questionnaire with nominal data was considered, as a some of the participants were patients with cognitive impairment.

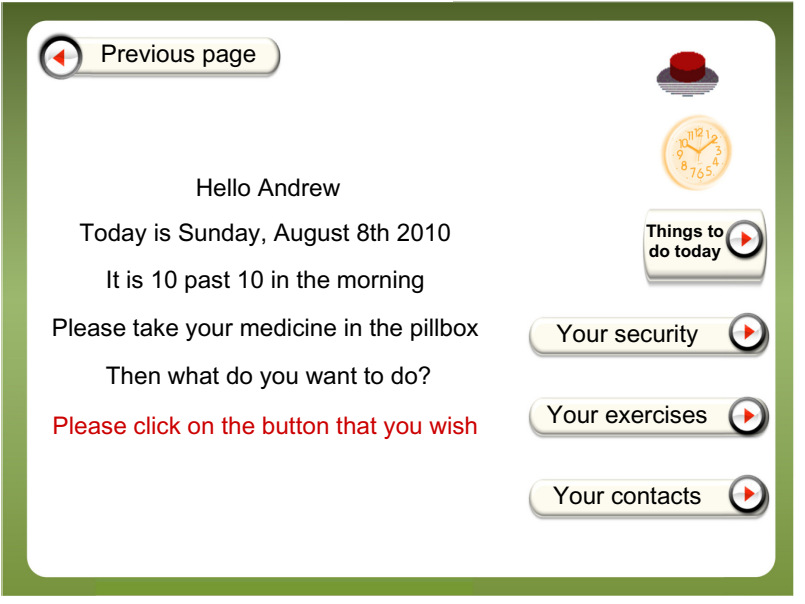

Figure I This screen displays a welcome message, and a variety of services are accessed through buttons.

Notes: Users may click either on the right side of the screen, where security, cognitive stimulation exercises, and contacts are located, or on the left side of the screen to see their agenda for the day. This area includes an electronic agenda, which is useful for effective planning and time management. Caregivers can easily use this feature as a way to structure the activities of patients by arranging reminders and a schedule that patients can consult throughout the day. If a call is received, an icon that is present on the left side of all available screens flashes. To accept the call, the user simply presses the icon and speaks into the device.

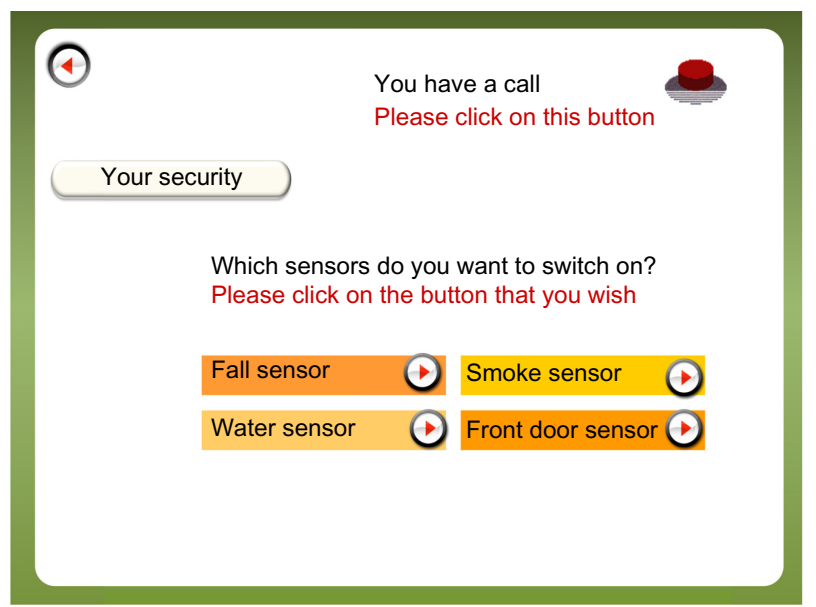

Figure $\mathbf{2}$ Through this screen, the user chooses which sensors are to be activated in their home.

Notes: The sensors, which include fall detectors, fire and water sensors, and front door sensors, are designed to detect emergencies and trigger automated calls for assistance. The security features of the system are customizable, in that the user has the capability of choosing which ones to employ.

To ensure the instrument's validity, the questions were first tested for readability, using people similar to the target populations, by a team member. In addition, during the present study, we asked the patients to rephrase each question in their own words to ensure comprehension of the questions.

The interviews were conducted by two members of the research team (a psychiatrist and a psychologist). One explained the functionality of the telecare system and then asked the prepared questions while encouraging comments. The other observed the participants' reactions while completing the questionnaire and recording the participants' comments. The participants were asked about their thoughts and opinions about the telecare system and its different components (sensors, medication and task reminders, online cognitive stimulation program, videoconference services).



Figure 3 This screen displays an example of a cognitive stimulation exercise. 


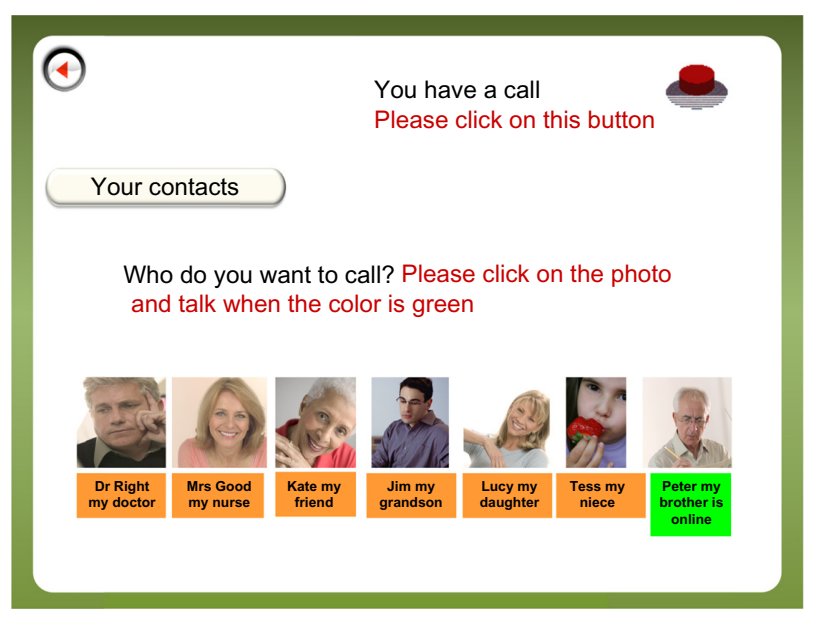

Figure 4 This screen displays photos of contacts.

Notes: Some of the contacts might be general practitioners, nurses, and family members. To call a contact, the user simply clicks on his/her photo and speaks. This feature could be used for teleconsultations with health care professionals or videoconferences with family and friends.

The main interview questions to the participants were focused on their perception of its usefulness for themselves in their daily life, their readiness to have it at home and to use it, and the potential disadvantages they could forecast (difficulty to use, high cost).

Each interview lasted approximately 40 minutes and consisted of a 20 minute explanation and a 20 minute questionnaire and discussion section.
The study was submitted to and approved by the local ethics committee. The patients and families gave their informed consent to participation in study.

\section{Analysis}

Quantitative data (such as age and MMSE scores) are reported as mean \pm standard deviation. Chi-square tests and paired $t$-tests were used when applicable to determine the statistical significance of qualitative variables; a probability value of 0.05 was considered statistically significant. In addition, material collected in the questionnaire was reported, measured in percentage of "yes" answers to the survey questions, and was analyzed by the use of Chi-square tests and summarized.

Qualitative material was also collected. Interviews were audiotaped and then transcribed. Then the analysis of the transcripts and the field notes were performed according to the inductive thematic analysis. ${ }^{11}$ After familiarizing themselves with the data and generating initial codes for data, a number of common emerging themes and issues were identified from the ideas expressed by the participants during the interviews.

\section{Results}

We evaluated the acceptance of home telecare technologies among patients suffering from cognitive impairment and their caregivers. This study provides some evidence that

Table 2 Questions to caregivers and patients

\begin{tabular}{|c|c|c|}
\hline Questions & $\begin{array}{l}\text { Caregivers, } \\
\text { yes }(\%)\end{array}$ & $\begin{array}{l}\text { Patients (AD + } \\
\text { MCI), yes (\%) }\end{array}$ \\
\hline $\begin{array}{l}\text { I. Do you think this telecare system, which can provide supervision by means of home sensors (detecting fire, } \\
\text { flood) or fall sensors (either video or worn at the patient's belt), might help the patient/you in urgent situations? }\end{array}$ & 83.3 & 75.8 \\
\hline $\begin{array}{l}\text { 2. Do you think such a telecare system of supervision would provide enough safety for the patient/you to } \\
\text { be left alone at home? }\end{array}$ & 53.3 & 38.7 \\
\hline $\begin{array}{l}\text { 3. Has the patient/have you already used or tested smart home technology such as sensors or an emergency } \\
\text { call system at home so far? }\end{array}$ & 13.3 & 11.3 \\
\hline $\begin{array}{l}\text { 4. Do you think the patient/you would be interested in being provided with medications, tasks, and } \\
\text { appointment reminders by this telecare system? }\end{array}$ & 76.7 & 53.2 \\
\hline $\begin{array}{l}\text { 5. Do you think the patient/you would be interested in practicing computerized cognitive exercises with this } \\
\text { telecare system? }\end{array}$ & 86.7 & 64.5 \\
\hline 6. Do you think the patient/you would be interested in having a medical consultation through this telecare system? & 76.7 & 62.9 \\
\hline $\begin{array}{l}\text { 7. Do you think the patient/you would be interested in using this telecare system to have a videoconference } \\
\text { system with his/her/your family and friends? }\end{array}$ & 66.7 & 54.8 \\
\hline 8. Do you think this telecare system might help the patient/you in activities of daily living? & 87.7 & 74.2 \\
\hline $\begin{array}{l}\text { 9. Do you think this telecare might help the patient/you to stay at home and delay the time at which the } \\
\text { patient/you enter a nursing home? }\end{array}$ & 56.7 & 38.7 \\
\hline $\begin{array}{l}\text { 10. Do you think the telecare system might put the patient/you at a risk of losing contact with his/her proxy } \\
\text { (risk of desocialization)? }\end{array}$ & 20 & 14.5 \\
\hline II. Does the patient/do you own or plan to own a computer at home? & 23.3 & 17.7 \\
\hline 12. Does the patient/do you have an Internet connection at home? & 16.7 & 8. I \\
\hline 13. Does the patient/do you are ready to use an Internet connection? & 6.7 & 1.6 \\
\hline 14. Would the patient/you be ready and accept to test such a telecare system at home? & 70 & 61.3 \\
\hline
\end{tabular}

Abbreviations: $\mathrm{MCl}$, mild cognitive impairment; $\mathrm{AD}$, Alzheimer's disease. 
patients and caregivers are receptive to the introduction of new telecare technologies. They appeared ready to accept its widespread use.

\section{Quantitative results}

Descriptive statistics and demographic characteristics are presented in Table 1. There were no significant differences between the caregivers related to sex composition $\left(\chi^{2}=2.2\right.$; $P=0.13$ ) or the relationship between the caregiver and the care recipient (eg, spouse versus offspring; $\chi^{2}=9.3 ; P=0.07$ ). There are no significant differences in education among groups. However, significant differences in age were found between caregivers and patients with MCI $(t=5.10 ; P=0.00)$ and between caregivers and patients with $\mathrm{AD}(t=4.92 ; P=0.00)$. Our target participant groups were not different in their mean age $(t=1.16 ; P=0.26)$.

The difference in MMSE scores between MCI and AD patients was significant $(t=8.39 ; P=0.00)$. The average

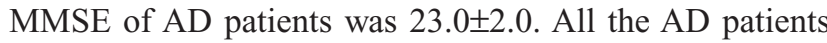
scored within the mild dementia range, using neurocognitive battery and educational level. This was important because for patients to fully participate in the evaluations, it was crucial that they be able to effectively communicate. It has been confirmed that this is possible in the early phase of dementia. $^{12,13}$

There was no significant difference in the three groups of participants regarding the responses to the questions. We show the responses of caregivers in comparison with both $\mathrm{AD}$ and MCI patients in Table 2.

There were no sex differences in perceptions of the system among the groups. No significant difference was found in the responses of women/men (20/10) to all the questions in the caregiver's group. The same was observed in the answers of women/men (45/17) to all the questions in the patients group (AD + MCI).

We did not find any significant difference in the answers of spouses/offspring (21/9) to all the questions in the caregiver's group.

\section{Qualitative results}

The telecare services (emergency detection, medicines and tasks reminders, cognitive stimulation, teleconsultation with professionals, and videoconference) were perceived as useful overall by both patients and families. Interestingly, although most patients reported that the system would be useful in emergency cases, they did not express as consistently that they would feel safe if left alone at home with the machine. Some replied that because they did not live close to their family members, the telecare system would make them feel more secure. A patient with MCI said he would be interested in implementing the telecare system in his home because he once had to wait more than 6 hours to be rescued after falling and not being able to get up. However, many patients expressed their preference for the presence of another person, be that a spouse, family member, or professional, rather than a machine if they were in an emergency situation in their home. Although most patients found the videoconference with professionals and family a useful service, many of them stated that they preferred to continue using the telephone because they were more familiar with it and had no reason to be dissatisfied with it.

Some patients expressed concerns about the complexity of the telecare system devices and their inability to use them. Several made statements to the effect of, "It would be difficult for me to remember how to use the telecare system. I would be stressed and anxious with the machine". Many patients also considered the telecare system services useful for elderly people with a greater level of cognitive deficits than themselves: "The telecare system would be useful for me if I had more deficits. But so far, I can manage by myself at home". Thus, these patients did not show readiness to adopt the telecare system, as they did not perceive any need for help in their daily activities. Other patients expressed concerns about privacy violations resulting from the use of the video surveillance system for fall detection. Those concerned about their privacy were more in favor of a fall detection sensor worn at the belt. Another common concern was the potential cost. "I will not be able to afford this machine", stated a patient.

As far as emergency detection was concerned, caregivers generally thought more highly of the system and thought this technology had more potential to improve their lives than the patients did. They stated that they would be reassured if they were called in case of emergency in the patient's home. "If something goes wrong with my father, this system can inform me immediately and I can deal with the problem at once". A spouse said she would have more freedom to go out and do some shopping or see her friends if she knew the telecare system would monitor her husband while she was away.

Caregivers also expressed positive feelings about the overall system: "If we had such a machine, I would take better care of my mother, who lives far from me". "The system will be useful because it will improve my quality of life". "This system could look after the patient during the day and night and could let the patient stay at home as long as possible". 
Although caregivers agreed that telecare systems have the potential to be quite useful and think they are very likely to be available in the future, they also expressed some negative opinions. A number of caregivers, most often spouses, denied the need for help in caring for the patient. "We do not need such a system now. I still can manage my husband's difficulties on my own. However, we might need it when the disease is progressed in my husband". Similar to the patents, one of the most frequently cited impediments by the caregiver was the telecare system's costs. Other concerns included the system's flexibility under the patient's command and the frustration of dealing with a machine instead of a human being: "I think that my mother would not choose this system because she would be anxious about being controlled by a machine".

\section{Discussion}

The successful introduction of health technology requires an in-depth understanding of how the proposed innovation is perceived by the users. The development of home telecare systems has already been shown to be useful in the elderly population, yet few authors have assessed their advantages in MCI and AD patients and in caregivers. ${ }^{3,14}$ The aim of the study was to evaluate the acceptance of home telecare technologies among patients suffering from cognitive impairment, as well as their caregivers. The results showed some evidence that patients and caregivers are receptive to the introduction of new telecare technologies. They appeared ready to accept its widespread use. Our results did not demonstrate significant differences in perception between patients and their caregivers with regard to telecare encounters across all the domains addressed.

The notion of a "smart home" was first introduced in the early 1980s, when the "intelligent building" concept gained popularity. This approach was conceived to use the intelligent implementation of consumer electronic devices, electrical equipment, and security devices in the automation of domestic tasks, easy communication, and safety with userfriendly controls. In its earlier development stages, the idea was oriented toward building a smart home environment for nondisabled persons for the simple purpose of enhancing home comfort. ${ }^{15,16}$ Recently, the same technology has become a bright prospect for people with special needs. Furthermore, there is a growing optimism that the quality of life of these people can be significantly improved by means of various modern technologies and, in particular, by intelligent houses. ${ }^{17,18}$ As a manifestation of this outlook, a new term, gerontechnology, was introduced by Graafmans to refer to a composite of gerontology and technology. ${ }^{19}$ Smart houses will have a strong, positive, and emotional effect on persons with physical and mental disabilities and older persons, enabling them to improve their quality of life, giving them privacy, and enabling them to experience the comfort of living in an ordinary house, as opposed to a hospital or nursing home. ${ }^{20}$

After a review of literature data on home telecare for elderly patients, Botsis and Hartvigsen ${ }^{3}$ surmised that home telecare had the potential to increase an elderly patient's independence and quality of life, as well as save costs for the authorities. ${ }^{3}$ Its possible applicability in cases of dementia and $\mathrm{AD}$ was evaluated. However, it was determined that there were no significant benefits of home telecare compared with traditional methods. The difficulties experienced by cognitively impaired elderly patients in learning how to use the necessary equipment seemed to be the principal deficiency of the system. However, further investigation is needed to draw any definite conclusions.

It was shown that home safety is a significant problem for caregivers of patients with $\mathrm{AD}$ and other dementias. ${ }^{21}$ Our results revealed that most of the patients and caregivers did not perceive the system to be safe enough for the patient to be left alone at home for long periods. The wife of one patient indicated that this system would not make her husband feel secure. Another comment indicated that memory problems would hinder appropriate use of the telecare system in an urgent situation. Stress also has the potential to obstruct the use of this technology. This impediment was both exhibited by the participants and mentioned as a concern. Minor problems encountered while using new systems tended to result in feelings of stress and loss of control.

A systematic review of the benefits of home telecare for the vulnerable elderly population indicated there is insufficient evidence of the effects of home safety and security alert systems. This is largely because the bulk of related studies focused on people suffering from diabetes or heart failure. However, there is significantly less evidence about the possible benefits of telecare for people suffering from conditions such as asthma, dementia, or depression. ${ }^{22}$

In our survey, the caregivers were most likely to be accepting of health technologies that assist in case of emergencies. They also generally approved of those technologies that enabled cognitive stimulation and reminded patients to take medications, as well as those that allowed patients to receive medical consultation by Internet. Overall, the majority of respondents agreed that they would be receptive to the use of telecare technologies related to a wide variety of situations. 
Patients also perceived the potential advantages of home telecare, especially those related to improvement in day-today living (Figure 5).

The chief concern of patients was the cost of telecare systems. Unfortunately, very few countries have comprehensive reimbursement policies for home telecare services. Another apparent limitation of these technologies is related to the small percentage of patients who have Internet access in their homes.

Loh et al conducted a study involving 20 patients suffering from dementia that revealed moderate differences between face-to-face health conferences and those conducted via videoconference. ${ }^{23}$ Poon et al conducted a study with 22 patients with dementia and other cognitive impairments. ${ }^{24}$ They demonstrated that telemedicine is a feasible, effective, and acceptable method of providing cognitive assessment and intervention. Another study relating to videoconferencing and clinical information systems in 140 patients with dementia found user acceptance to be satisfactory and there to be no significant differences from the traditional assessment methods. ${ }^{25}$

Engström et al showed that the perception of patient family members (22 persons) of using individualized passage alarms, motion sensors, fall detectors, and Internet communication were generally positive. ${ }^{26}$

Another study on using devices with wearable reminders and alarms in 38 cognitively impaired patients and caregivers found no change in quality-of-life measures but high user satisfaction, as well as a reduction in the cost of services. ${ }^{27}$

An important issue related to the use of telecare technology is whether there should be a special legal framework for long-distance health care. The characteristics of home telecare should be made clear so that users have a thorough understanding of the limitations as well as the capabilities involved in this technology. It is also crucial to maintain an active and open relationship with the possible ethical problems that such systems imply. Moreover, it is necessary to develop specific guidelines for the delivery of these services to the cognitively impaired elderly population. These issues should be the focus of future research efforts. ${ }^{3}$

Further investigation also is recommended, using larger sample sizes across a range of telecare contexts. Such research is necessary to enhance the understanding of barriers to telecare implementation and to help identify which telecare initiatives are most likely to be successful if made available on a large scale. Data related to the cost-effectiveness of technological interventions are also needed. Other possible topics of future research include the effects of technology on other outcomes, such as caregiver burden. It would also be practical to consider the costs and benefits of technology relative to current practices. A number of issues concerning privacy, safety, and quality control are also worthy of further consideration. ${ }^{28}$

Some limitations of the study should be acknowledged. Participants gave their opinions about the functionalities of the telecare system at the research unit, but they did not actually test these functionalities in conditions similar to those at their own homes. For instance, in a real-life situation, participants might not have felt comfortable leaving the patient at home alone with the system. In addition, although the participants confirmed they understood the explanations

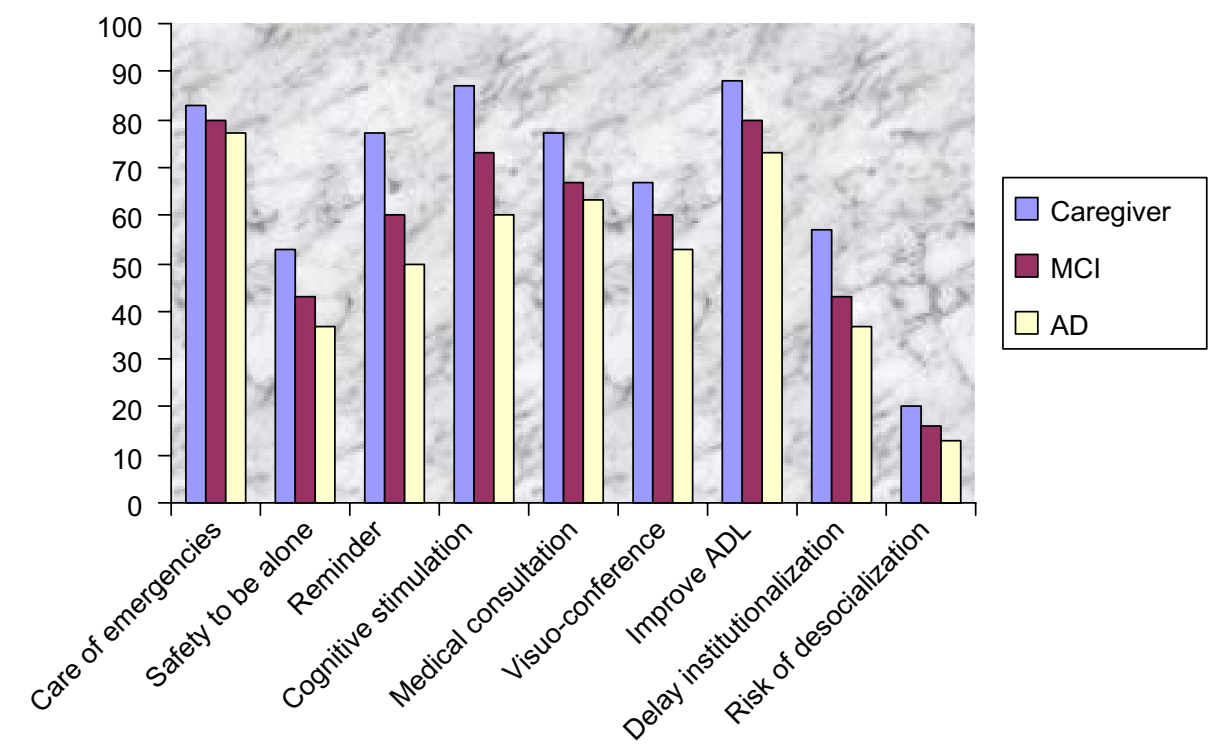

Figure 5 Graphical representation of patients and caregivers' opinions toward the usability, benefits, and risks of telecare systems obtained out of the survey. Abbreviations: $\mathrm{MCl}$, mild cognitive impairment; $\mathrm{AD}$, Alzheimer's disease; $\mathrm{ADL}$, activities of daily living. 
about the telecare services depicted through interfaces displayed on a computer with a touch screen, one cannot exclude that another design of the interfaces might have been more effective for the patients and caregivers. In addition, the interpretation of results is limited because of the small number of participants. However, despite these limitations, the study demonstrated that potential users had a positive attitude toward home telecare technologies. They agreed that home telecare and smart houses could improve their quality of life and communication for patients and caregivers. Regarding home telecare, the cognitive stimulation program earned the highest proportion of positive responses, followed by the care of emergencies. There were no significant sex and age (spouse/offspring) or patient/caregiver differences in the acceptance of telecare system.

We are currently developing a prototype of this system and assessed some components, including an appropriate interface tailored to patients and caregivers; communication between patients, caregivers, and professionals via Web camera; computerized cognitive stimulation for patients; and educational programs for caregivers.

\section{Consent}

The study presented has been approved by the local ethics committee. The patients and families gave their informed consent before participating in this study.

\section{Acknowledgments}

We thank the patients and caregivers who agreed to participate in the study. This work has been financed by the National Research Agency through RNTS (National Health Technology Network) program (Project TANDEM ANR 05-RNTS-01202) and the Foundation Mederic Alzheimer.

\section{Disclosure}

The authors report no conflicts of interest in this work.

\section{References}

1. National Institute of Aging. Progress report on Alzheimer's disease: Taking the next steps (NIH publication No 004859). Washington, DC: US Department of Health and Human Services; 2000.

2. Eisdorfer C, Czaja SJ, Loewenstein DA, et al. The effect of a family therapy and technology-based intervention on caregiver depression. Gerontologist. 2003;43(4):521-531.

3. Botsis T, Hartvigsen G. Current status and future perspectives in telecare for elderly people suffering from chronic diseases. J Telemed Telecare. 2008;14(4):195-203.

4. Ludwig W, Wolf KH, Duwenkamp C, et al. Health-enabling technologies for the elderly - an overview of services based on a literature review. Comput Methods Programs Biomed. 2012;106(2):70-78.

5. Agrell H, Dahlberg S, Jerant AF. Patients' perceptions regarding home telecare. Telemed J E Health. 2000;6(4):409-415.
6. Bertera EM, Tran BQ, Wuertz EM, Bonner A. A study of the receptivity to telecare technology in a community-based elderly minority population. J Telemed Telecare. 2007;13(7):327-332.

7. Folstein MF, Folstein SE, McHugh PR. "Mini-mental state". A practical method for grading the cognitive state of patients for the clinician. J Psychiatr Res. 1975;12(3):189-198.

8. American Psychiatric Association. Diagnostic and Statistical Manual of Mental Disorders. 4th ed. Washington, DC: American Psychiatric Press; 1994.

9. McKhann G, Drachman D, Folstein M, Katzman R, Price D, Stadlan EM. Clinical diagnosis of Alzheimer's disease: report of the NINCDSADRDA Work Group under the auspices of Department of Health and Human Services Task Force on Alzheimer's Disease. Neurology. 1984;34(7):939-944.

10. Portet F, Ousset PJ, Visser PJ, et al; Report of the MCI Working Group of the European Consortium on Alzheimer's Disease. Mild cognitive impairment (MCI) in medical practice: a critical review of the concept and new diagnostic procedure. J Neurol Neurosurg Psychiatry. 2006;77(6):714-718.

11. Braun V, Clarke V. Using thematic analysis in psychology. Qual Res Psychol. 2006;3(2):77-101.

12. Hubbard G, Downs MG, Tester S. Including older people with dementia in research: challenges and strategies. Aging Ment Health. 2003;7(5): 351-362.

13. Nygård L. Responses of persons with dementia to challenges in daily activities: a synthesis of findings from empirical studies. Am J Occup Ther. 2004;58(4):435-445.

14. Faucounau V, Wu YH, Boulay M, Maestrutti M, Rigaud AS. Caregivers' requirements for in-home robotic agent for supporting communityliving elderly subjects with cognitive impairment. Technol Health Care. 2009;17(1):33-40.

15. Shwehdi MH, Khan AZ. A power line data communication interface using spread spectrum technology in home automation. IEEE Trans Power Deliv. 1996;11(3):1232-1237.

16. Brooks RA. The intelligent room project: Cognitive technology. In Proc. 2nd Int. Cognitive Technology Conference, Aizu Wakamatsu, 1997:271-278.

17. Warren S, Craft R. Designing smart health care technology into the home of the future. Proc. 1st Joint BMES/EMBS Conference, Atlanta, GA, 1999:677.

18. Lindström JI. In: Bühler C, Knops H, Andrich R, editors. "From R\&D to Market Products - The TIDE Bridge Phase," in Assistive Technology Added Value to the Quality of Life, C Marin "cek. Amsterdam, The Netherlands: IOS; 2001:688-692.

19. Graafmans J, Taipale V, Charness N. Gerontechnology: A Sustainable Investment of the Future. Amsterdam, The Netherlands: IOS; 1997.

20. Stefanov DH, Bien Z, Bang WC. The smart house for older persons and persons with physical disabilities: structure, technology arrangements, and perspectives. IEEE Trans Neural Syst Rehabil Eng. 2004;12(2): 228-250.

21. Lach HW, Chang YP. Caregiver perspectives on safety in home dementia care. West J Nurs Res. 2007;29(8):993-1014.

22. Barlow J, Singh D, Bayer S, Curry R. A systematic review of the benefits of home telecare for frail elderly people and those with long-term conditions. J Telemed Telecare. 2007;13(4):172-179.

23. Loh PK, Ramesh P, Maher S, Saligari J, Flicker L, Goldswain P. Can patients with dementia be assessed at a distance? The use of Telehealth and standardised assessments. Intern Med J. 2004;34(5):239-242.

24. Poon P, Hui E, Dai D, Kwok T, Woo J. Cognitive intervention for community-dwelling older persons with memory problems: telemedicine versus face-to-face treatment. Int J Geriatr Psychiatry. 2005;20(3):285-286.

25. Lee JH, Kim JH, Jhoo JH, et al. A telemedicine system as a care modality for dementia patients in Korea. Alzheimer Dis Assoc Disord. 2000;14(2):94-101.

26. Engström M, Lindqvist R, Ljunggren B, Carlsson M. Relatives' opinions of IT support, perceptions of irritations and life satisfaction in dementia care. J Telemed Telecare. 2006;12(5):246-250. 
27. Vincent C, Reinharz D, Deaudelin I, Garceau M, Talbot LR. Public telesurveillance service for frail elderly living at home, outcomes and cost evolution: a quasi experimental design with two follow-ups. Health Qual Life Outcomes. 2006;4(1):41.
28. Czaja SJ, Rubert MP. Telecommunications technology as an aid to family caregivers of persons with dementia. Psychosom Med. 2002;64(3):469-476.

\section{Publish your work in this journal}

Medical Devices: Evidence and Research is an international, peerreviewed, open access journal that focuses on the evidence, technology, research, and expert opinion supporting the use and application of medical devices in the diagnosis, treatment and management of clinical conditions and physiological processes. The identification of novel devices and optimal use of existing devices which will lead to improved clinical outcomes and more effective patient management and safety is a key feature. The manuscript management system is completely online and includes a quick and fair peer-review system. Visit http://www. dovepress.com/testimonials.php to read real quotes from authors.

Submit your manuscript here: http://www.dovepress.com/medical-devices-evidence-and-research-journal 